\title{
In vivo and in vitro cell-based model of lung adenocarcinoma from patients with pleural effusion
}

\author{
Mikulas POPOVIC ${ }^{1, *}$, Yiling LIU ${ }^{1}$, Erika LATTOVA², Dean MANN³, Sabrina CURRELI ${ }^{1}$, Zbyněk ZDRÁHAL², Martin EDELMAN ${ }^{5,6}$, Joseph BRYANT ${ }^{1, *}$ \\ ${ }^{1}$ The Institute of Human Virology, University of Maryland School of Medicine, Baltimore, Maryland, USA; ${ }^{2}$ Central European Institute for \\ Technology, Masaryk University, Brno, Czech Republic; ${ }^{3}$ The Pathology Department, University of Maryland School of Medicine, Baltimore, \\ Maryland, USA; ${ }^{4}$ National Centre for Biomolecular Research, Faculty of Science Masaryk University, Brno, Czech Republic; ${ }^{5}$ Marlene and \\ Stewart Greenebaum Comprehensive Cancer Center, Baltimore, Maryland, USA; ${ }^{6}$ Fox Chase Cancer Center, Philadelphia, Pennsylvania, USA
}

*Correspondence: mpopovic@ihv.umaryland.edu; jbryant@ihv.umaryland.edu

Received September 6, 2020 / Accepted December 20, 2020

\begin{abstract}
Lung adenocarcinoma (LAC) is a common and aggressive form of lung cancer that is increasing in incidence among never smokers at a younger age. Current treatment of patients with LAC is insufficient and there is a need for identification of effective biomarkers and development of therapeutic targets. These demands require also improved models for in vivo and in vitro experimentation. In this study, we describe the establishment of two LAC cell lines, named LuCa-3 and LuCa-6. Both were derived from pleural effusion (PE) cells of LAC patients (L3 and L6) and readily propagated as tumor xenografts in immunodeficient mice. PE cells from the patient L6 exhibited also the capacity for in vitro growth and were cultured in two forms: (i) as a suspension growing cell population, labeled LuCa-6S, composed of non-clumping single cells; and (ii) as a monolayer-like culture, labeled LuCa-6A, exhibiting tight cell-to-cell and to culture surface adherence. Unique features of these two sublines and their cell clones are the capacity to convert from a non-clumping single-cell suspension into the adherent growth pattern and vice versa. Immunostaining of patients' tumor tissue xenografts and cultured subline cells displayed markers specific for the phenotype of human LAC. LuCa-6S and LuCa-6A cells did not reveal a noticeable disparity in quantitative growth characteristics. However, a number of differences were detected between these two cell populations manifested in detection or intensities of antigen expressions on the cell surface (CD133, SFTPC) and in the nucleus (TTF-1) including pluripotent (OCT-4, SOX-2, NANOG) genes in cancer stem-like cells (CSCs). Dissimilarities between these two sublines were also detected in $\mathrm{N}$-glycan profiles and in the sensitivity to natural killer cells. Salient features of these subline cell populations are responsiveness to selective upregulation of the pluripotent genes in subsets of CSCs via conversion of their growth patterns and/or by using culture stem media with growth factors. The described in vivo/ in vitro model enables broader experimental approaches in studies of lung adenocarcinoma.
\end{abstract}

Key words: cell-based model of LAC, lung adenocarcinoma, growth pattern conversion, OCT-4, SOX-2, NANOG, pluripotent genes

Despite recent therapeutic advances in lung cancer, the disease remains the most common cause of cancer-related death in the United States [1-3]. There are ongoing research efforts to discover new biomarkers for early diagnosis, prognosis, and prediction of response to treatment [3]. Moreover, this undertaking also led to in-depth studies of tumor driving cell subsets, termed cancer stem cells (CSCs) [4-9]. Non-small-cell lung cancer (NSCLC) is a heterogeneous and largest group of LC tumors composed of three major histological types [10]. Lung adenocarcinoma (LAC) is the most common type of this group [10-15]. While still primarily a disease related to smoking, an increasing incidence of LAC among never smokers at a younger age has been observed in recent years $[12,13]$. Furthermore, LAC exhibits diverse characteristics as well, particularly at the molecular level. Studies focused on genetic alterations of LC resulted in the identification of additional subtypes of LAC $[11,14,15]$. Of note, progress in LC detection using low-dose computed tomography (LDCT) indicates that a number of patients diagnosed in the early stages of the disease will substantially increase [16]. Although the vast majority of initial detections by LDT are non-cancerous nodules, over $60 \%$ exhibit the LAC histology among the identified tumors [3, 14-18].

In recent years, biomedical cancer research has required extensive sources of human tumor material. This requirement has been met to a certain degree by systematic in vitro establishment of cancer cell lines obtained from a number 
of laboratories and deposited in the American Type Culture Collection (ATCC) $[19,20]$. In the case of LC cell lines, over $75 \%$ originated from the National Cancer Institute (Bethesda, Maryland) and Hamon Cancer Center (Dallas, Texas) [19]. Several of these LC cell lines were also included in the lung cancer cell line panel that had been characterized at the molecular level $[19,20]$. This scale of human tumor material for research has been considerably enlarged by the development of patient-derived xenografts (PDX). PDX mouse models were developed using fresh tumor tissues from patients as well as in vitro maintained LAC cells with defined oncogene drivers. These models enable one to study molecular mechanisms of tumor growth, the potential response of patients to anti-cancer therapy and drug resistance [19-22], and generated exceptional accumulation of basic knowledge of the cellular and molecular biology of the disease [15, $20-24]$. Despite the extensive progress in LC models [20, 25, 26], recent reports using newly established LAC cell lines have challenged some recent observations related to CSCs as well as earlier theories about the epithelial-mesenchymal transition (EMT) process $[27,28]$. Taking into consideration the extensive heterogeneity of LAC, additional expansion of in vitro and in vivo models can substantially contribute to our understanding of this severe form of malignancy.

Here we report the establishment and characterization of two cell lines propagated as a PDX in mice, named LuCa-3 and LuCa-6, originating from two LAC patients with pleural effusion (PE), respectively. Besides a standard in vivo propagation, primary PE cells from the second patient L6 exhibited also an exceptional capacity for in vitro growth and these cells have been cultured long-term as two separate sublines. The LuCa-6S subline has been propagated as a non-adherent culture in a distinctive form of single-cell suspension, and the second adherent LuCa-6A subline exhibited a more common type of monolayer-like growth pattern. Utilizing growth characteristics of the established cell lines of LAC, we also demonstrate the suitability of this in vivo/in vitro model for wide-ranging experimental studies, including minority cell-subsets exhibiting attributes of CSCs.

\section{Patients and methods}

Patients' specimens. Pleural effusion (PE) specimens were obtained from two patients with LAC in the advanced stages displaying an increased positivity for epidermal growth factor receptor (EGFR). These de-identified samples with coded numbers L3 and L6 were collected after informed consent was approved by the Institutional Review Board of the University of Maryland. PE containing cells were processed according to standard procedure. Cell sediments from PE were washed by Dulbecco's phosphate-buffered saline (DPBS). Separation of viable cells from the PE sediment containing also erythrocytes was obtained by centrifugation in the Ficoll-Hypaque gradient (Pharmacia, Uppsala, Sweden) and cell pellets were subsequently two times washed with DPBS by centrifuga- tion. The viability of cells was determined by the trypan blue exclusion assay.

Tumorigenicity of primary and cultured cells. All in vivo experiments were performed in the Animal Core Facility, Institute of Human Virology, in accordance with the University of Maryland IACUC guidelines, under the approved research protocols. Immunodeficient mice of NOD-scid IL2 $\gamma^{\text {null }}$ and athymic nude mice $(i n u / n u)$ strains from The Jackson Laboratory (Bar Harbor, ME) were used for in vivo propagation of patients' primary LAC. Following cellseparation, primary PE cells were re-suspended in serumfree RPMI1640 (Gibco) and subcutaneously (s.c.) inoculated in the right flank of a mouse in concentrations from 2 to $3 \times 10^{6}$ cells/mouse in $200 \mu \mathrm{l}$ media. Primary cells from both patients were inoculated into mice. The cell line LuCa-3 from the patient L3 was propagated only as a tumor xenograft. The second cell line LuCa-6 from patient L6 has been also propagated in vitro under non-adherent and standard culture conditions. Both sublines, LuCa-6S and LuCa-6A, were evaluated for tumorigenicity by s. c. inoculation of cells in concentrations of $1-2 \times 10^{6}$ cells/mouse and the LuCa-6A cells were also inoculated in 10-fold dilutions. Mice were inspected for tumor growth two to three times per week. A mouse with a tumor size of $\geq 1 \times 1 \mathrm{~cm}$ was sacrificed and tumor tissues, lung, spleen, liver, and lymph nodes were further investigated.

HLA typing. The established cell lines, $\mathrm{LuCa}-3$ and LuCa-6, were subjected to HLA typing by using the QIAxcel ${ }^{\circ}$ system (Qiagen). According to the manufacturer's instructions, RNAs were extracted from the $\mathrm{LuCa}-3$ and $\mathrm{LuCa}-6$ tumor tissues as well as from both, LuCa-6A and LuCa-6S sublines cultured in vitro.

In vitro cell culturing. Cells were cultured in a complete medium (RPMI1640-CM) containing 20\% fetal calf serum (FCS) and antibiotics (Gibco). Re-suspended cells in the concentration of $1 \times 10^{6} / \mathrm{ml}$ of RPMI1640-CM from the patient L6 were seeded in standard T25 and T75 tissue culture flasks (Corning) and into 6-well plates of ultra-low attachment (Corning) and cultured at $37^{\circ} \mathrm{C}$ in $5 \% \mathrm{CO}_{2}$. Cell cultures were maintained by replacing $70-90 \%$ volume of culture media with fresh RPMI-CM twice a week. Following trypsin (Gibco) exposure, cell cultures in flasks of the adherent LuCa-6A were subcultured in the concentration of $2-3 \times 10^{5}$ cells $/ \mathrm{ml}$, while the LuCa-6S was subcultured by diluting cells in suspension with about $1 \times 10^{6}$ cells $/ \mathrm{ml}$ in the ratio of 1:4 with fresh RPMI1640-CM. The viability of cells was monitored by the trypan blue exclusion. Cell numbers were determined by a hemocytometer. Cancer stem medium (CSM) (ProMab Biotechnology, Richmond, CA) was utilized for the growth of CSCs according to the company's instructions. Insulin (Novo Nordisk) was used in the concentration of 2.0 and $4.0 \mu \mathrm{g} / \mathrm{ml}$ of CSM.

Cell cloning. Single-cell cloning was performed by a limiting dilution as previously described [4]. Cells were diluted in the concentrations of one cell/ $300 \mu \mathrm{l}$ conditioned RPMI1640-CM. The conditioned medium contained 70\% 
fresh RPMI1640-CM and 30\% of centrifuged and filtered media harvested from the cultures of the established LuCa-6S subline. Cells in a volume of $100 \mu \mathrm{l}$ (one cell per three wells) were seeded into plates with "V" shape bottom (Corning) and maintained under humidified conditions. The growth of cloned cells in wells was inspected regularly and cells of outgrown clones were further expanded using 96, 48, and 24 well plates (Corning) with a flat bottom.

Immunohistochemistry (IHC) and immunofluorescence (IF) analyses. Histological examination of LAC, which included hematoxylin-and-eosin (H\&E), IHC, and IF staining, was performed using formalin-fixed paraffinembedded (FFPE) sections of patient tumor xenografts L3 and L6. FFPE sections of 4 to $5 \mu \mathrm{m}$ thickness were subjected to deparaffinization, rehydration, and antigens retrieval. For IHC, to reduce background staining and quench endogenous activities, a series of blocking procedures were performed including incubation with 5\% normal goat serum in PBS. After blocking, sections were incubated with diluted primary antibodies overnight at $4{ }^{\circ} \mathrm{C}$, followed by room temperature incubation with biotinylated goat antibodies targeting the primary antibodies [29]. VENCASTAIN ABC reagents and HPR or AP substrates were used for color development [https://www.qiagen.com/ us/resources/resourcedetail?id=d7b1c257-0a56-4a5f-b52c$6572 \mathrm{fb} 7 \mathrm{dec} 9 \mathrm{a} \& \mathrm{lang}=\mathrm{en}]$. Hematoxylin was used for the nuclear staining. In addition, IF was performed on tissue sections as detailed below.

IF staining of cultured cells comprised the following steps: i) preparation of cytospin slides; $i$ ) fixation and permeabilization of cells; iii) primary antibody incubation overnight at $4{ }^{\circ} \mathrm{C} ;$ iv) then, incubation for $1-2$ hours at room temperature with selected (Green/Alexa 488, Red/cy3, or Alexa 555) fluorochrome-conjugated secondary antibodies (diluted 1:200) directed against the species of primary antibodies [29]. DAPI used for nuclear staining and $\operatorname{IgG}$ from non-immunized animals served as negative controls.

Table 1. Growth of lung adenocarcinoma cells from L3 and L6 patients in immunodeficient mice following subcutaneous inoculation.

\begin{tabular}{lcc}
\hline Cells and cell lines & Cell number & $\begin{array}{c}\text { Mice with tumor/ } \\
\text { inoculated mice }\end{array}$ \\
\hline L3 pleural effusion cells ${ }^{*}$ & $2.0 \times 10^{6}$ & $3 / 3$ \\
LuCa-3 tumor tissue cells ${ }^{* *}$ & $1.5 \times 10^{6}$ & $2 / 2$ \\
L6 pleural effusion cells & $3.0 \times 10^{6}$ & $2 / 2$ \\
LuCa-6S & $2.0 \times 10^{6}$ & $2 / 2$ \\
LuCa-6S & $1.0 \times 10^{6}$ & $2 / 2$ \\
LuCa-6A & $2.0 \times 10^{6}$ & $2 / 2$ \\
LuCa-6A & $1.0 \times 10^{6}$ & $2 / 2$ \\
LuCa-6A & $1.0 \times 10^{5}$ & $3 / 3$ \\
LuCa-6A & $1.0 \times 10^{4}$ & $2 / 3$ \\
\hline
\end{tabular}

Notes: ${ }^{\star} 200 \mu \mathrm{l}$ of cells were inoculated s. c. into nude mice; in all other in vivo experiments NOD mice were used for the evaluation of tumor growth; ${ }^{* *}$ viable stored cells at $-140^{\circ} \mathrm{C}$ were used for the inoculation of NOD mice originating from the $\mathrm{L} 3$ patient's primary tumors grown in nude mice
The following antibodies with working dilutions were used in this study: anti-keratins CK-7, clone OV-TL 12/30 in dilutions 1:100-200 of mouse IgG1, $196 \mathrm{mg} / \mathrm{l}$ c\#7018 (Dako) and IgG2a anti-CK-20, clone Ks20.8 dilution 1:100 (Invitrogen \#MA5-13263); antibodies to mouse fibroblasts Er-Tr7 (rat IgG2a, Novus Biologicals \#NB100-64932) and endothelial cells CD31, clone D1, (mouse IgG2b, Santa Cruz \#sc-46694), both (1:200); rabbit IgG antibodies to pluripotent stem cell markers from Abcam: NANOG \#ab-109250 (1:200), Oct-4 \#ab181557, (1:300), and Sox-2 \#ab-9249 (1:135); mouse IgG1 antibodies to cytoplasmic and nuclear antigens: transmembrane glycoprotein (prominin-1) CD133/1 \#130-090422, Miltenyi Biotec (1:100); anti-TTF-1 (thyroid transcription factor), clone 8G7G3/1, Santa Cruz \#sc-53136 (1:150); anti-CD44 (8E2F3), cell surface adhesion receptor, Novus Biological \#NBP1-47386ss (1:200); anti-SFTPC, surfactant protein C [aa 144-173], LS-Biosciences \#LS-B9161 (1:200). Fluorochrome-conjugated secondary antibodies from Invitrogen were used as follows: green Alexa 488 goat anti-mouse IgG1 (\#ab21121) and anti-rabbit IgG H+L (\#ab11008), anti-rat IgG H+L (\#ab11006), red Alexa Fluor 555-goat-antimouse IgG1 (\#ab 21127) or IgG1 H+L (\#ab 21422), anti-rat IgG $\mathrm{H}+\mathrm{L}$ (\#ab 21434) or Cy3-goat anti-rabbit IgG $\mathrm{H}+\mathrm{L}$ (\#ab 111-165-144) from Jackson Immunoresearch Laboratories. As reported [29], secondary antibody dilutions were either determined by testing or used as recommended by supplier.

RNA isolation and quantitative real-time-PCR (qPCR). Qiagen's QuantiTect SYBR-green PCR technique was used in this study (https://www.qiagen.com/us/ resources/resourcedetail?id $=\mathrm{d} 7 \mathrm{~b} 1 \mathrm{c} 257-0 \mathrm{a} 56-4 \mathrm{a} 5 \mathrm{f}-\mathrm{b} 52 \mathrm{c}-$ $6572 \mathrm{fb} 7 \mathrm{dec} 9 \mathrm{a} \& l a n g=e n)$ [29]. Total RNA was isolated from cultured cells using RNAeasy plus mini kit (ID74034). RT2 First strand kit (ID330401) was used for cDNA synthesis. Cell numbers for RNA extraction ranged from $1-5 \times 10^{6}$ cells and yield was at least $40 \mathrm{ng} / \mu \mathrm{l}$ RNA or higher. SYBR green ROX qPCR Mastermix (ID 330522) and $1 \mu$ l primer were used for each quantitative reaction. The PCR reactions were performed on an instrument of ABI Prism 7000. Genespecific primers purchased from Qiagen were as follows: NANOG (Cat\#: PPH17032E); POU5F1 [OCT-4] (Cat\#: PPHO2394E), SOX-2 (Cat\#: PPHO2471A), PROM1 [CD133] (Cat\#: PPHO2400A) for cell surface marker detection and thyroid transcription factor 1 (TTF-1) (Cat\#: PPH09477A). Housekeeping gene GAPDH, glyceraldehyde 3-phosphate dehydrogenase (Cat\#: PPH00150F) was used in the qPCR. Data analyses were performed by using Qiagen Data analysis software and Microsoft excel to calculate the mean \pm standard deviation and $\mathrm{p}$-value and to create graphics.

\section{Results}

Xenografting and tumorigenicity of patients' LAC cells in immunodeficient mice. Cells from PE of LAC patients L3 and L6 were assessed in vivo for tumor growth and propagation as a PDX in immunodeficient mice. As shown in Table 1 , 
patients' PE cells were inoculated either into nude or NOG mice in the concentrations 2 and $3 \times 10^{6}$ cells/mouse, respectively. Tumors were generated in all inoculated animals after 8 to 10 weeks (Supplementary Figure S1). Subsequently, viably frozen primary tumor cells from mice originating from patient L3 were grown in NOG mice by inoculating s. c. $1.5 \times 10^{6} \mathrm{cells} / \mathrm{mouse}$. This positive in vivo passage indicated that LAC cells from this patient could be sustainably propagated as a PDX tumor cell line, termed LuCa-3. The development of the tumor line in vivo enabled a more detailed morphological and phenotypical characterization of the LAC cells from PDX. As mentioned above, PE cells from the L6 patient inoculated into NOG mice generated tumors. In addition, LAC cells originating from $\mathrm{PE}$ of this patient have been in vitro propagated in two forms as sublines. Cells of both sublines, suspension-growing LuCa-6S and adherent LuCa-6A cells, generated tumors following s. c. inoculation of $1 \times 10^{6}$ cells/animal in NOG mice. Furthermore, the LuCa-6A cells were also inoculated in 10-fold dilutions, and, even at the low concentration of $1 \times 10^{4} \mathrm{cell} / \mathrm{s} / \mathrm{animal}$, generated tumors in 2 out of 3 inoculated mice (Table 1). Relevantly, both strains of mice with s. c. growing tumors, either from L3 or L6 patients, frequently presented with metastasis, particularly into the lungs. As shown in Supplementary Figure S1, cells of metastasized lesions in the lungs were positive for the TTF-1 marker specific for human LAC [30,31]. Additionally, as shown in Supplementary Table S1, there are distinct differences in HLA profiles between LuCa-3 and LuCa- 6 cell lines making it possible to monitor their identity.
In vitro propagation of LuCa-6 cell line and growth characteristics. In addition to in vivo growth of PE cells from the L6 patient, both cultured subline cell populations, LuCa-6S and LuCa-6A, were also readily propagated in vitro continuously for over 6 months. Under the same culture conditions, PE cells from the patient L3 did not grow in vitro. LuCa-6S subline grown in suspension was primarily composed of a non-clumping round-shaped single-cell population of uniform morphology with the presence of few giant cells. A generation of small cell clumps was rarely observed in cultures. As previously reported on in vitro growth of LAC $[32,33]$, the second LuCa-6A subline exhibited a monolayer-like growth pattern with a noticeable cellto-cell and surface-culture adherence, and was composed mainly of cells with polygonal and bipolar morphology. An example of two different growth patterns of LuCa-6S and LuCa-6A is depicted in Figures $1 \mathrm{~d}$ and 1e. However, no substantial differences were determined between these two cell populations in their doubling-time during the growth phase or cell yields per milliliter at the terminal cell density.

Conversion of the growth pattern in LuCa-6 sublines and cell clones. LuCa-6S cells grown in a suspension are readily propagated in vitro as an adherent population by seeding cells in the standard culture vessels with an adherent surface. Likewise, cells released into the culture medium from the adherent subline LuCa-6A could be readily grown in the ultra-low adherence plates in a suspension form. To substantiate this observation of growth pattern conversion, the single-cell cloning was performed. The plating efficiency
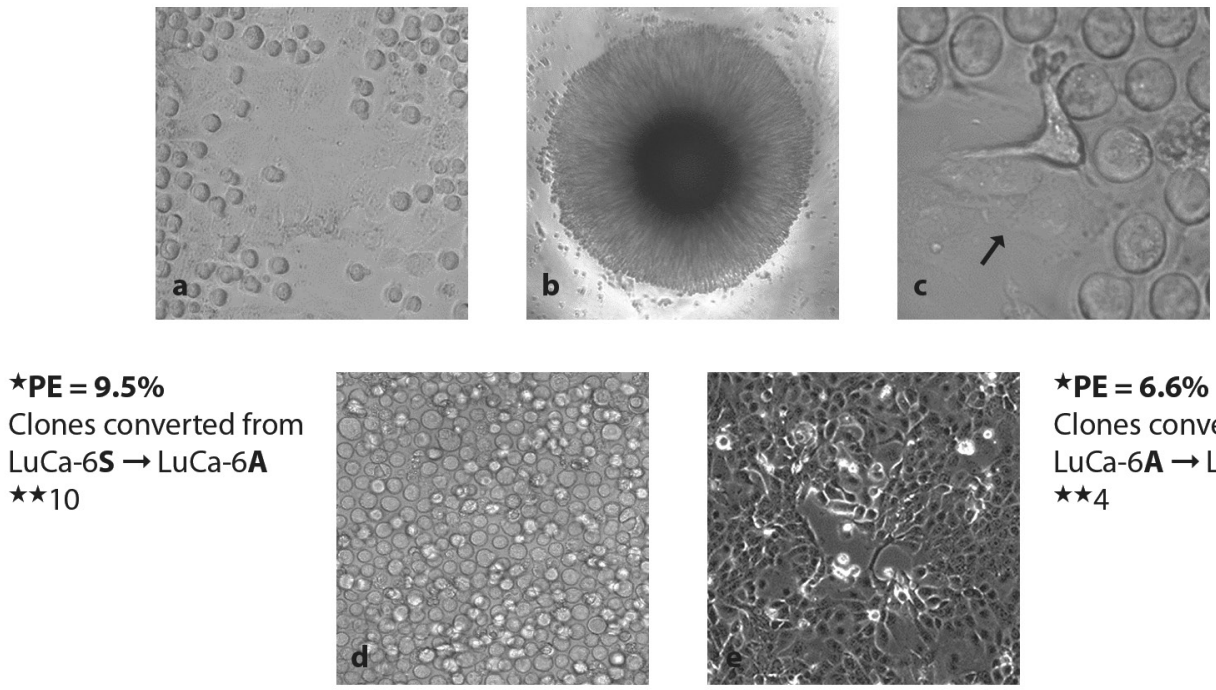

$\star \mathrm{PE}=\mathbf{6 . 6 \%}$

Clones converted from LuCa-6A $\rightarrow$ LuCa-6S $\star \star 4$

Figure 1. Conversion of the growth patterns in LuCa-6S and LuCa-6A subline cell populations into the adherent or the suspension form of growth. ${ }^{*}$ Plating efficiency $\left({ }^{*} \mathrm{PE}\right)$ of LuCa-6S subline grown in a suspension. ${ }^{*} \mathrm{PE}$ of LuCa-6A subline grown as an adherent monolayer-like cell population. Ten cell clones from LuCa-6S ${ }^{* *}$ and four clones from LuCa-6A $\mathrm{A}^{\star *}$ cell lines were propagated in both forms in culture. a) Outgrowth of a cloned cell population composed of adherent and round cells $[10 \times]$; b) early outgrowth of a cell clone in a V-well plate (for details of cloning see "Material and Methods") [4x]; c) the arrow points to adherent cells in close vicinity to round-shaped cells [40×]; d) the growth pattern of LuCa-6S subline composed of non-clumping single cells propagated in a suspension using the ultra-low adherence culture plates [10×]; e) monolayer-like growth pattern of LuCa6 A subline propagated in the adherent form under the standard culture conditions $[10 \times]$. 
of LuCa-6S and LuCa-6A was 9.5\% and 6.6\%, respectively. As shown in Figure 1, ten cell clones were isolated and expanded from the suspension LuCa-6S subline and 4 clones from the adherent subline LuCa-6A. In the early phases of a cell colony outgrowth from a single-cell, there are adherently growing
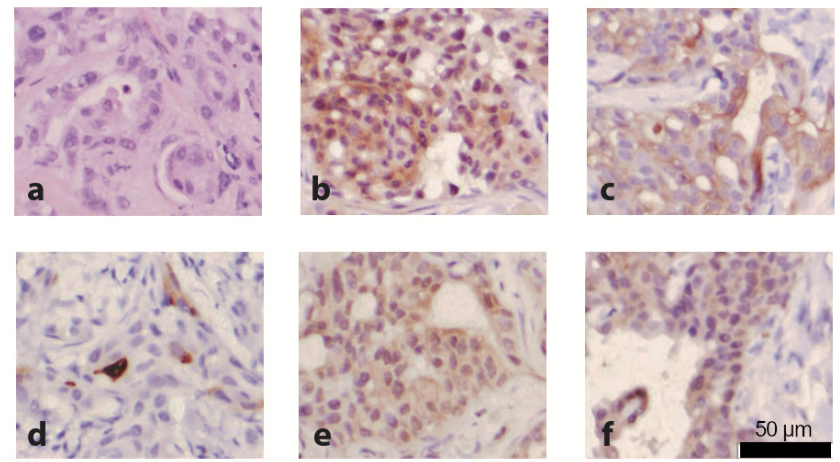

Figure 2. Phenotypic characterization of the LaCa-3 tumor tissue xenograft from a nude mouse. Cells were recovered from pleural effusion of L3 patient with LAC and propagated as a xenograft in mice. a) H\&E staining depicts morphology of the LAC tumor xenograft. Immunoreactivities for specific markers as follows: b) TTF-1; c) CK7; d) CK20; e) SFTPC; f) CD-44. Notice negative staining for CK20.

LuCa-6S
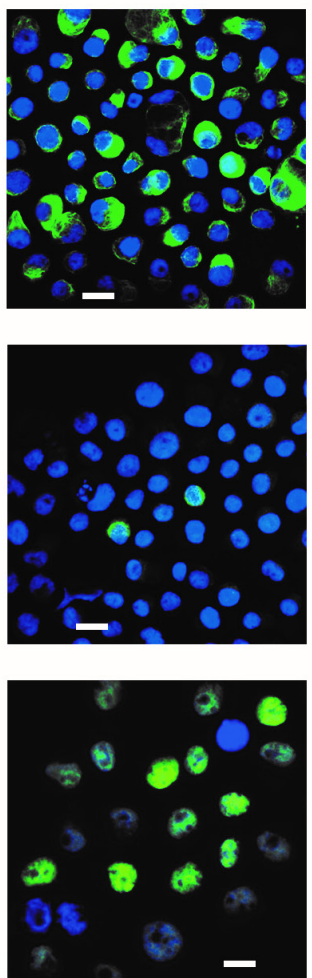

LuCa-6A
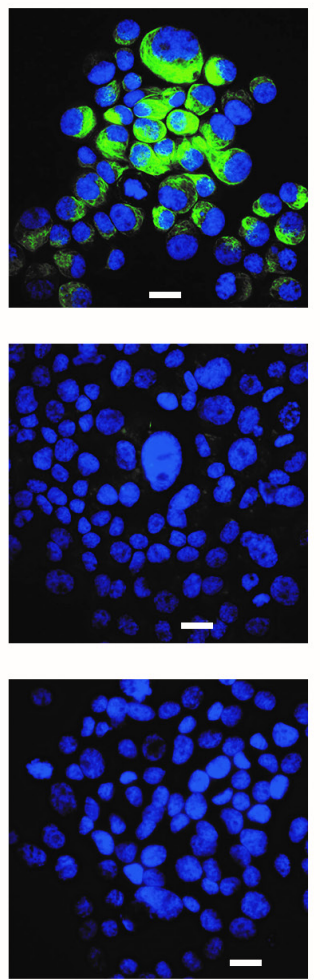

cells and mostly round-shaped cells, which are loosely in contact with each other (Figures 1a-1c). The suspension or adherent growth pattern of a cloned cell population further depended on whether cells were seeded in culture plates with the ultra-low adherence or in standard tissue culture vessels (e.g., T25). All 10 clones from LuCa-6S growing in a suspension were readily convertible into the adherent growth and vice versa. The same pattern of growth changes exhibited all four clones from the adherent LuCa-6A subline. Currently, a number of LAC cell lines have been reported, however, none of them displayed this form of growth in suspension composed of non-clumping singe-cells with such growth pattern versatility as these two LuCa-6 sublines.

Antigenic markers of the tumors from PE cells of L3 and L6 patients. Tumor tissues generated as PDX from PE of L3 and L6 patients and also by the inoculation of in vitrogrown LuCa-6 cells into nude and NOG mice were subjected to morphological and phenotypic characterization by the immunochemistry (IHC) [30-32]. As depicted in Figure 2a, the morphology of H\&E staining of the tissues from PEFF tumors showed a solid pattern of LAC morphology with a tendency for glandular formations. IHC staining of these specimens was performed by antibodies to antigenic
CD-133

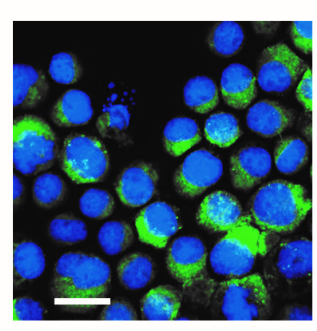

SFTPC

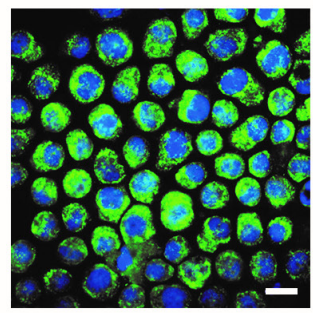

CD-44

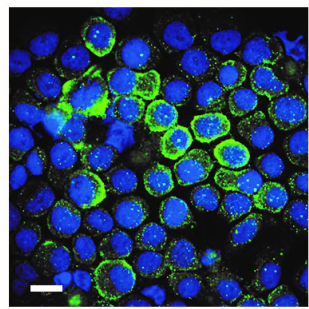

LuCa-6A
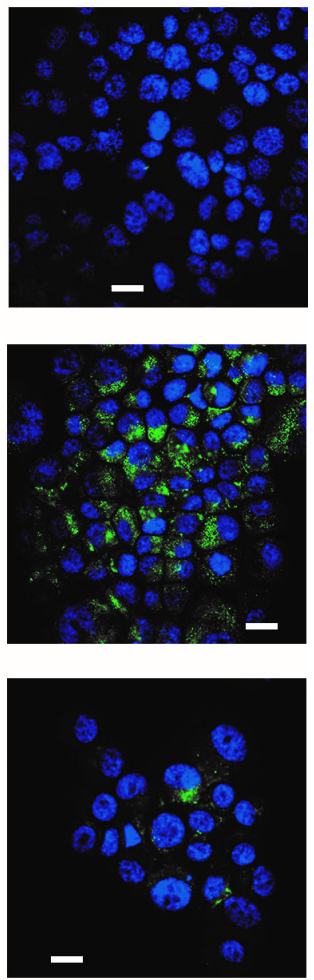

Figure 3. Phenotyping of cells in long-term cultured sublines LuCa-6S propagated in a suspension and LuCa-6A grown as the adherent monolayerlike cultures. Cells of both sublines display CK7+, CK20-, and SFTPC+ phenotype. Other antigenic markers such as CD133 and TTF-1 were readily detected in LuCa-6S cells, while these markers were low or undetectable in LuCa-6A cells by IF, size bar: $15 \mu \mathrm{m}$. However, the expression of these two antigens rapidly declined in the course of LuCa-6S cells conversion into an adherent growth form during short-term in vitro culturing (for details see also Supplementary Figure S3). 
markers distinctive for human LAC, namely cytokeratins CK7 and CK20, the surfactant protein C (SFTPC) produced by alveolar cells, the thyroid transcription factor TTF-1, and also to the cell adhesion glycoprotein CD-44. In the case of LuCa-3 tumors, Figures $2 \mathrm{~b}-2 \mathrm{f}$ show clear nuclear staining for TTF-1 and cytoplasmic staining for markers CK7, SFTPC, CD-44, but negative for CK20. The same staining pattern for these markers was obtained in the tumor xenograft tissues from patient L6, irrespective of the PDX source originating either from primary PE cells or LuCa-6 cell variants. Staining only for TTF-1 and CK7 markers is shown in Supplementary Figures S1 and S2. These results clearly demonstrate the presence of markers characteristic for LAC in vivo propagated LuCa-3 and LuCa-6 lines, which are consistent with histopathology and clinical diagnosis [30-32]. The only difference between tumors of these two lines was observed in the detection of pluripotent stem cell markers expressed in CSCs [34-37]. In the case of LuCa-3, OCT-4 and markers were not detected, while in LuCa-6 tumor tissue OCT-4 was also negative but positive for the pluripotent marker NANOG. Supplementary Figures S2a and S2b show the nuclear-stained NANOG+ cells localized within the tumor tissue xenograft. As depicted in Supplementary Figures S2cS2e, mouse cells, which were detected by specific antibodies to fibroblasts $(\mathrm{Er}-\mathrm{Tr}+)$ and endothelial $(\mathrm{CD} 31+)$ cells, surround the CK7+ LuCa- 6 tumor cells. The NANOG+ cells were localized within the area of CK7+ and TTF-1+ human tumor cells and not mouse cells.
Phenotyping of subline LuCa-6S and LuCa-6A cells. Characterization of cultured cells of both sublines, LuCa-6S and LuCa-6A, was focused on the detection of earlier reported specific LAC markers [30-32]. Fixed cells on cytospin slides from both sublines were assessed with the same panel of antibodies utilized for the characterization of xenograft tumor tissues. Briefly, the antibodies used were as follows: CK7, CK20, TTF-1, CD-133, SFTPC, and CD-44. As depicted in Figure 3, LuCa-6S cells exhibited a specific reactivity with all of these antibodies with the exception of SK20. Thus, these cells were positive for CK7, SFTPC and did not react with CK20. Importantly, the adherent LuCa-6A cells were also positive for these two markers and negative for CK20. This staining pattern is in line with the adenocarcinoma markers detected in tumor xenografts and indicates that both sublines are LAC cells. However, as implied by the IF data, the expression of antigenic markers localized either in the nucleus or the cell surface membrane can fluctuate or even decline to undetectable levels as in LuCa-6A cells cultured as an adherent population. As shown in Supplementary Figure S3, the IF positivity for TTF-1 and particularly CD-133 in LuCa-6S cells, a notable decline occurs during the conversion into the adherent growth pattern within 6 to 11 days of in vitro culturing.

Induction of pluripotent genes expression and cell markers in LuCa-6 sublines. Detection under standard culture conditions. Finding NANOG+ cells in the LuCa-6 tumor xenograft initiated a broader analysis of the markers
25

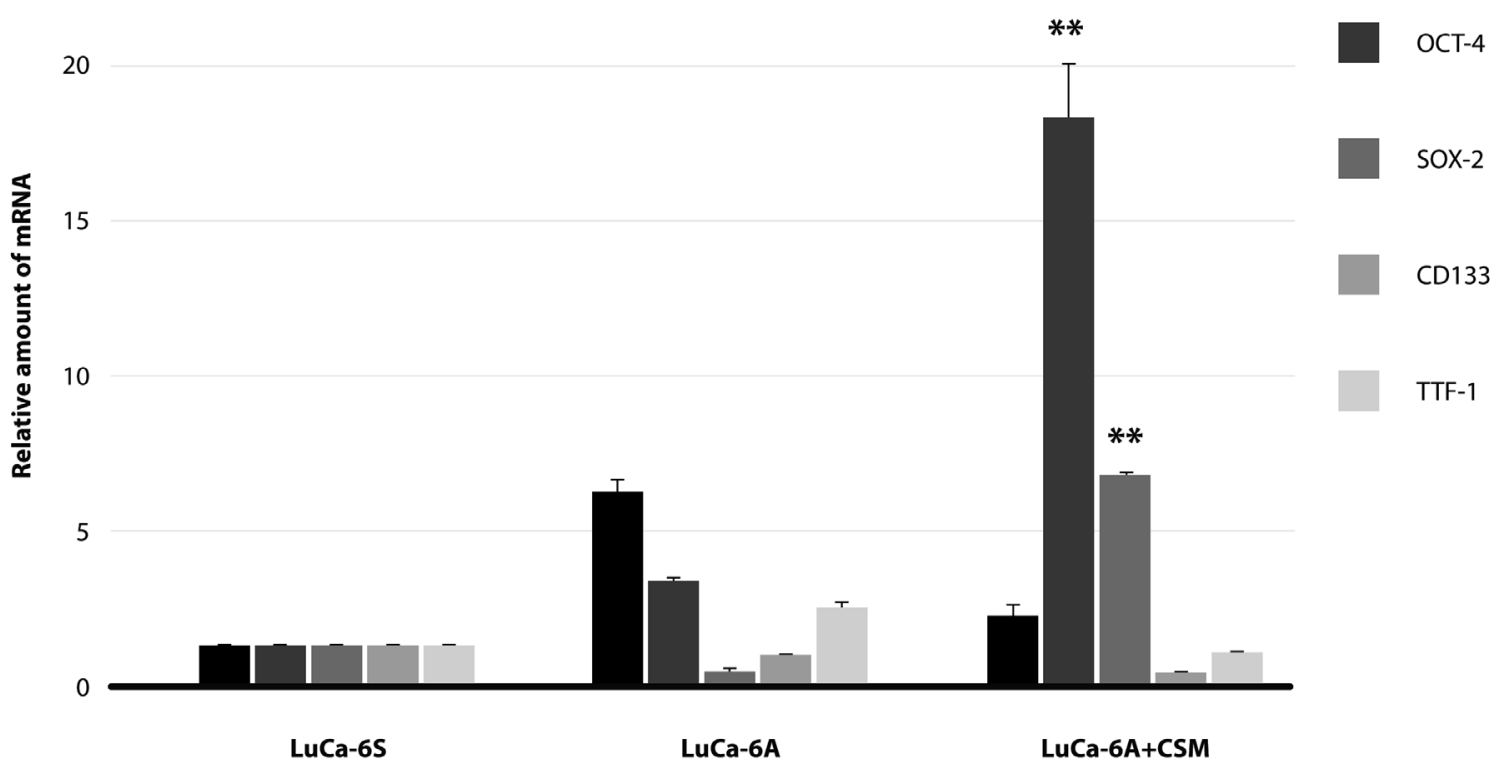

NANOG

CT-4

SOX-2

133

TF-1

Figure 4. Detection of CSC and LAC markers by real-time $\mathrm{QPCR}$ in LuCa-6S and LuCa-6A cells cultured under the standard culture conditions and in the cancer stem medium (CSM). As compared to LuCa-6S, the expression of NANOG, OCT-4, and TTF-1 were two to three-fold higher and SOX-2 lower in LuCa-6A cells. Culturing of these LuCa-6A cells in CSM with insulin $(2 \mu \mathrm{g} / \mathrm{ml})$, OCT-4, and SOX-2 expression significantly increased $\left({ }^{* \star} \mathrm{p}<0.01\right)$, while the expression of NANOG, CD-133, and TTF-1 decreased. 
characteristic for cancer stem-like cells in both LuCa-6S and LuCa-6A sublines. Cells of these sublines cultured under the standard conditions in RPMI1640-CM were subjected to analyses using real-time qPCR. Detection of mRNA expression of antigenic markers CD-133, TTF-1, and pluripotent genes such as NANOG, OCT-4, and SOX-2 was performed and described data are at least from two independent experiments. The housekeeping gene GAPDH was utilized as an internal control for quantifying mRNA expression. As shown in Figure 4, the expression of pluripotent genes OCT-4 and NANOG was about 2- to 4-fold higher and SOX-2 lower in the adherent $\mathrm{LuCa}-6 \mathrm{~A}$ cells as compared to the $\mathrm{LuCa}-6 \mathrm{~S}$ cell population grown in suspension. Differences in CD-133 and TTF-1 expressions between these two sublines were detectable, although less apparent. Furthermore, two procedures were applied for induction of these genes in both subline cell populations: one, using cancer stem medium (CSM) with insulin and the second one, by converting cell growth pattern from suspension into an adherent form of the growth.

Induction by CSM with insulin. LuCa-6A cells were cultured in CSM with insulin up to 11 days in the plates of ultra-low adherence before subjected to an assessment of RNA level by qPCR. As shown in Figure 4, the LuCa-6A cultured cells displayed a substantial increase in the expression of OCT-4 and SOX-2, while the expression of NANOG, TTF-1, and CD133 declined. As compared to LuCa-6A maintained in RPMI1640-CM, the increase in RNA expression of OCT-4 and SOX-2 was significant in the LuCa-6A cells cultured in CSM with insulin, respectively. The induction experiment of the pluripotent genes with CSM and insulin in LuCa-6S was not performed due to the rapid decline of cell viability. However, a modified culture medium in combination with growth factors enabled to induce the expression of pluripotent genes OCT-4, SOX-2, and particularly NANOG in the Luca-6S cells. Increased expression of NANOG was prominent in the second generation of tumor spheres (Supplementary Figure S4). Noteworthy, the NANOG positive cells were also detected in the tumor xenograft following the inoculation with LuCa-6S cells (Supplementary Figure S2B).

Switching the growth pattern from a suspension into an adherent. Given that the adherent LuCa-6A cells effectively expressed OCT -4 and SOX- 2 by culturing in CSM with insulin that prompted to assess the expression of the pluripotent genes including also CD133 and TTF-1 in LuCa-6S cells following the conversion into an adherent population. LuCa-6S cells were cultured as an adherent cell population under the standard culture conditions for 10 days. Subsequently, the adherent growing cells of LuCa-6S, termed LuCa-6S/A, were subjected to induction of pluripotent genes. The expression of these genes was induced by culturing of these LuCa-6S/A cells in CSM with insulin using the same culture conditions as for the induction of genes in LuCa-6A cells. Compared to LuCa-6S cells grown only in the suspension, the expression of OCT- 4 and SOX-2 increased significantly in the converted

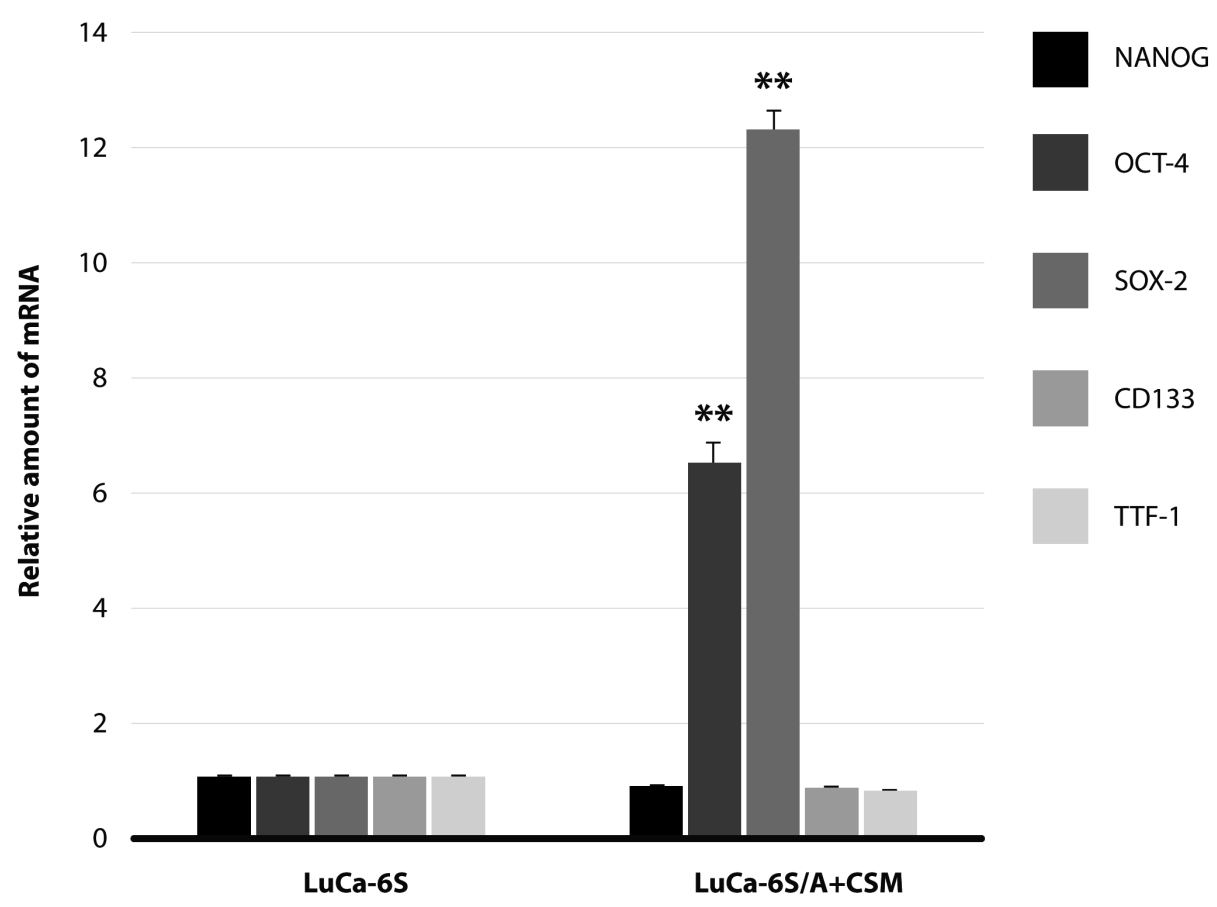

Figure 5. Induction of CSC and LAC markers in LuCa-6A/S cells converted from the suspension to the adherent monolayer-like growth pattern. Conversion of LuCa-6S cells into the adherent growth form was carried out by a short-term culturing in standard culture conditions for 10 days. Induction of markers' expression was attained by subsequent culturing of cells in CSM with $2 \mu \mathrm{g} / \mathrm{ml}$ insulin for 11 days. As determined by qPCR, in contrast to LuCa-6S cells, the converted LuCa-6A/S cells to the adherence showed a significant increase in the expression of OCT-4 and SOX-2 (** p<0.01). 
LuCa-6A/S cell population as shown in Figure 5. In addition, as presented in Supplementary Figure S5, ongoing analyses of LuCa-6S cell clones by IF, particularly clone 3, a majority of cells expressed SOX-2 distinctly localized in the nucleus (Supplementary Figure S5). This observation is consistent with a high level of SOX-2 expression in the converted LuCa6S/A cells detected by qPCR.

Thus, the established LuCa- 6 sublines exhibited versatile growth characteristics with the capacity of cells to respond to changes in culture conditions by selective down- or upregulated expression of several antigenic markers including pluripotent stem cell genes.

\section{Discussion}

Both, LuCa-3 and LuCa- 6 cell lines derived from the PE of two LC patients generate tumors, which were readily propagated in vivo as xenografts following the s. c. inoculation of cells in immunodeficient mice. PE cells from patient L6 were also established in vitro and long-term propagated in two forms. The LuCa-6S subline was grown in suspension and the adherent subline LuCa-6A was cultured as a monolayer-like population. The tumor tissues from both patients as well as in vitro propagated sublines exhibited markers (CK7+/CK20-, SFTPC+, and TTF-1+) characteristic for the human LAC phenotype [29]. Thus, the tumor xenografts from L3 and L6 patients as well as two sublines represent an in vivo/in vitro cell system that could be classified as a PDX-MI (patient-derived xenograft-minimal information). This experimental model corresponds most likely to the second Clinical/Patient module [21-23]. Despite the limitations inherently present in a PDX-MI, the established in vivo/in vitro cell lines potentially have a broader experimental use due to the availability of cultured sublines with rare and beneficial growth characteristics.

The LuCa-6S subline has a unique growth pattern among LC cell lines established in vitro because it is readily propagated in a suspension and can be converted into the adherent form and vice versa. A cell line from LAC with these characteristics has not yet been reported. Even small cell lung cancer (SCLC), which generates PE in patients more frequently than LAC, the established SCLC cell lines display poor cell adherence to culture surfaces but grow in sizable cell-clamps [36, 37]. However, the LuCa-6S cell culture is composed of the non-clumping single-cells, which can be readily cloned and propagated as tumor xenografts. The growth characteristics of these cells provide a number of experimental advantages such as: a) a more accurate assessment of the interactions utilizing cytokines, infectious agents, and cytolytic cells with largely homogeneous non-clumping cell population maintained in suspension; b) evaluation of differences in expression of cell or viral antigens between the suspension and the adherent cell populations; c) simplifies in-depth analyses of cell subsets with CSC characteristics and finally d) the access to LAC cells from PE is easier enabling to validate observations using fresh non-cultured tumor cells. Finally, LuCa- 6 cells can potentially serve as a host-cell for the study of SARS-CoV-2 (coronavirus) as implied by the origin of LAC from pneumocytes II and expression of the surfactant protein C (SFTPC) specific for these cells. Pneumocytes II are one of the targets and a host cells expressing the hACE2 receptor for this virus and co-localization of SARS-CoV-2 and SFTPC in these cells has been documented [38-42]. In addition, utilizing the LuCa-3 tumor line propagated only in vivo could aid to discern conceivable changes in cell population associated with in vitro culturing.

This study of LAC showed dissimilarities in the expression of pluripotent genes and antigenic markers between cells of LuCa-6S and LuCa-6A sublines. Differences between sublines have been further expanded in our ongoing studies of $\mathrm{N}$-glycan profile analyses by mass spectrometry (MS) [42] in relation to the CSC markers expression and the sensitivity of these LuCa- 6 cell populations to natural killer (NK) cells [42]. As listed in Supplementary Figure S6, differences in expression of $12 \mathrm{~N}$-glycans were detected between cells of these two sublines by MS analyzes comprising a broad spectrum of glycans with $\mathrm{m} / z$ values from 1007 to 3928.4 . Importantly, a distinct difference between LuCa-6S and LuCa-6A cells was found in resistance and sensitivity to NK cells. Supplementary Figure S7 shows that LuCa-6S cells were completely resistant to NK cells, while adherent LuCa-6A cells exhibited NK sensitivity in a dose-dependent manner. Thus, these data of our current investigations are in line with the earlier findings on the differences between cell populations of these two sublines.

Recently, Tiran et al. [28] reported on two different LAC cell subpopulations derived from a patient's primary tumor with innate resistance to the treatment of LC. One subpopulation of cells propagated as a spheroid cell culture with epithelial characteristics and aggressive growth. This cell population was also therapy-resistant and expressed CSC markers, while the second subpopulation of cells expressing mesenchymal characteristics lacked these markers, though exhibited unlimited growth potential and was propagated in vitro as an adherent population. These data seem to be in contrast with our observation. However, as mentioned above, LAC is a highly heterogeneous tumor. Recent studies using deep sequencing for the genome characterization of LACs demonstrated that $60 \%$ of cases were oligo- and polyclonal cell populations, whereas $40 \%$ were monoclonal $[9,15,20]$. Furthermore, the established in vivo/in vitro LuCa-3 and LuCa- 6 cell lines originate from patients with advanced LC disease.

LAC is frequently associated with the development of malignant $\mathrm{PE}$, which occurs during disease progression [35]. The process of cancer progression is also accompanied by increased mutations in driver genes of LAC and likely contributes to CSC heterogeneity within tumor cells $[24,35]$. LAC cells in PE represent cell population released from tumor tissues via the mechanism of epithelial-mesen- 
chymal transition (EMT) characterized with downregulated cell-to-cell adhesion [34, 43]. The cultured LuCa-6S cells in suspension are composed of non-clumping singlecells resembling the LAC population of PE with decreased cell-to-cell adhesion. A distinct feature of the LuCa-6S cell population is its capacity to convert into the adherent form and switch back in suspension growth pattern. Cloned cell populations of both sublines retain this capacity (Figure 1). In cancer progression, cells can gain the potential to adapt reversible and transient states with the ability to convert from one form into another. Beerling et al. [27] defined this development in metastasizing cancer cells as epithelialmesenchymal plasticity (EMP). The metastasis requires the invasion of tumor cells into tissues, which is generated by the EMT process involving cells with CSC characteristics. However, the EMP aids migration and does not enhance the stem cell potential [27]. Thus, the established LuCa-6 sublines, which are readily converted into suspension and adherent forms could contribute to further elucidation of EMT and EMP processes.

A number of studies for identification and isolation of CSCs from NSCLC have been focused on these minority cell subsets utilizing cell surface glycoproteins CD133 and CD44 of in vitro established cell lines [20, 44-48]. However, the expression of these molecules is variable in various LC cell lines, and contradictory results were obtained in these studies, possibly due to the shortcomings inherent to in vitro propagated cells $[19,20]$. Findings were reported on isolated CD133+ or CD44+ cell populations with the ability for self-renewal and tumor initiation capacity in mice [44-46], though other reports demonstrated the same growth characteristics with CD133-or CD44- cell subpopulations $[47,48]$. Even though LAC cell lines propagated in vitro and/or in vivo do not fully represent primary tumor cells, they remain a powerful tool in providing a number of benefits. For instance, microenvironment-generated by cancer-associated fibroblasts were evaluated using in vitro cell based model of EMT resulting in the detection of several new transcription factors and early EMT markers [49]. Recently, a battery of NSCLC cell lines mostly derived from LAC, particularly the cell line NCI-H1568 with notable heterogeneity, were employed to analyze the cellular origin and drug resistance of CSCs in heterogeneous cancer cell populations [35]. To avoid shortcomings and preserve genomic integrity of human tissue specimens, in vivo and in vitro models have adapted experimental procedures with short-term durations. In cases of NSCLC in PDX mouse models, targeted therapy assessments were done using patients' tumor tissues in low-passaged PDX [21]. Similarly, the sphere-forming assay of tumor specimens from NSCLC was evaluated after a short-term in vitro cultivation [51]. Frequently, observations obtained from in vitro studies are subsequently validated in vivo. We have recently reported an effective procedure for $\mathrm{N}$-glycan profiling of tissue specimens, which was first developed using in vitro established tumor cell lines and then was successfully applied for fresh tumor specimens obtained from patients with LAC $[50,52]$.

In conclusion, the above-described differences between sublines of LuCa-6 cells demonstrated extensive shifts in markers including expression of pluripotent genes characteristic for CSC-like cell subsets, which can be effectively enhanced by changing the culture conditions. Specifically, the expression of pluripotent CSC markers can be selectively up- or downregulated in cells of both sublines by using different CSM, growth factors and by switching cell growth patterns. Availability of cell subsets with robust expression of pluripotent genes and their corresponding controls enables to determine those cell surface markers, which are closely associated with CSC-like cells.

Supplementary information is available in the online version of the paper.

Acknowledgments: We thank R. C. Gallo for supporting this project, H. Davis for his administrative support and Hieu Tran for technical assistance, S. Rollins for HLA typing, K.G. Hankey for performing NK cytotoxicity assay. We are grateful to M. Salvato for editing the manuscript and critical comments. This research was sponsored by the University of Maryland School of Medicine through departmental funding of Animal Core Facility, Institute of Human Virology, and by CEITEC Proteomics Core Facility of CIISB, Instruct-CZ Centre, supported by MEYS CR (LM2018127).

\section{References}

[1] SIEGEL RL, MILLER KD, JEMAL A. Cancer Statistics 2019 CA: Cancer J Clin 2019 69:7-34. CA Cancer J Clin 2019; 69: 7-34. https://doi.org/10.3322/caac.21551

[2] DE GROOT PM, WU CC, CARTER BW, MUNDEN RF. The Epidemiology of lung cancer. Transl Lung Cancer Res 2018; 7: 220-233. https://doi.org/10.21037/tlcr.2018.05.06

[3] ROBLES AI, HARRIS CC. Integration of multiple "OMIC" biomarkers: A precision medicine strategy for lung cancer. Lung Cancer 2017; 107: 50-58. https://doi.org/10.1016/j. lungcan.2016.06.003

[4] GORAI I, YANAGIBASHI T, TAKI A, UDAGAWA $\mathrm{K}$, MIYAGI $\mathrm{E}$ et al. Uterine carcinosarcoma is derived from a single stem cell: An in vitro study. Int J Cancer 1997; 72: 821-827. https://doi.org/10.1002/(sici)10970215(19970904)72:5<821::aid-ijc19>3.0.co;2-b

[5] ERAMO A, LOTTI F, SETTE G, PILOZZI E, BIFFONI M et al. Identification and expansion of the tumorigenic lung cancer stem cell population. Cell Death Differ 2008; 15: $504-$ 514. https://doi.org/10.1038/sj.cdd.4402283

[6] LEVINA V, MARANGONI AM, DEMARCO R, GORELIK E, LOKSHIN AE. Drug selected human lung cancer stem cell: Cytokine network, tumorigenic and metastatic properties. Cancer Res 2010; 70: 338-346. https://doi.org/10.1158/00085472.CAN-09-1102 
[7] SUTHERLAND KD, BERNS A. Cell origin of lung cancer. Mol Oncol 2010; 4: 397-403. https://doi.org/10.1016/j. molonc.2010.05.002

[8] MATHER JP, ROBERTS PE, PAN Z, CHEN F, HOOLEY $J$ et al. Isolation of cancer stem like cells from human adenosquamous carcinoma of the lung supports a monoclonal origin from a multipotential tissue stem cell. PLoS One 2013; 8: e79456. https://doi.org/10.1371/journal.pone.0079456

[9] Testa U, Castelli G, Pelosi E. Lung cancers: molecular characterization, clonal heterogeneity and evolution, and cancer stem cells. Cancers (Basel) 2018; 10: 248. https://doi. org/10.3390/cancers 10080248

[10] MOLINA JR, YANG P, CASSIVI SD, SCHILD S, ADJEI AA. Non-small cell lung cancer: epidemiology, risk factors, treatment, and survivorship. Mayo Clin Proc 2008; 83: 584-594. https://doi.org/10.4065/83.5.584

[11] HASHIMOTO T, TOKUCHI Y, HAYASHI M, KOBAYASHI Y, NISHIDA K et al. Different Subtypes of Human Lung Adenocarcinoma Caused by Different Etiological Factors. Am J Pathol 2000; 157: 2133-2141. https://doi.org/10.1016/ s0002-9440(10)64851-1

[12] SUN S, SCHILLER JH, GAZDAR AF. Lung cancer in never smokers-different disease. Nat Rev Cancer 2007; 7: 778-790. https://doi.org/10.1038/nrc2190

[13] THUN MJ, HANNAN LM, ADAMS-CAMPBELL LL, BOFFETTA P, BURLING JE et al. Lung cancer occurrence in never-smokers: an analysis of 13 cohorts and 22 cancer registry studies. PLoS Med 2008; 5: e185. https://doi.org/10.1371/ journal.pmed.0050185

[14] THE CANCER GENOME ATLAS RESEARCH NETWORK. Comprehensive molecular profiling of lung adenocarcinoma. Nature 2014; 511: 543-550. https://doi. org/10.1038/nature13385

[15] SKOULIDIS F, HEYMACH VJ. Co-occuring alterations in non-small-cell lung cancer biology and therapy. Nat Rev Cancer 2019; 19: 495-509. https://doi.org/10.1038/s41568019-0179-8

[16] NATIONAL LUNG SCREENING TRIAL RESEARCH TEAM, ABERLE DR, ADAMS AM, BERG CD, BLACK WC et al. Reduced lung-cancer mortality with low-dose computed tomographic screening. N Engl J Med 2011; 365: 395-409. https://doi.org/10.1056/NEJMoa1102873

[17] GARDINER N, JOGAI S, WALLIS A. The revised lung adenocarcinoma classification-an imaging guide. J Thorac Dis 2014; 6: S537-S546. https://doi.org/10.3978/j.issn.20721439.2014.04.05

[18] MELTON N, LAZAR JF, MORITZ TA. A Community-based Pulmonary Nodule Clinic: Improving Lung Cancer Stage at Diagnosis. Cureus 2019; 11: e4226. https://doi.org/10.7759/ cureus. 4226

[19] GAZDAR AF, GIRARD L, LOCKWOOD WW, WAN LL, MINNA JD. Lung cancer cell lines as tools for biomedical discovery and research. J Natl Cancer Inst 2010; 102: 13101321. https://doi.org/10.1093/jnci/djq279

[20] MULSHINE LJ, UJHAZY P, ANTMAN M, BURGESS MC, KUZMIN I et al. From clinical specimens to human cancer preclinical models - a journey the NCI-cell line database -25 years later. J Cell Biochem 2019; 121: 3986-3999. https://doi. org/10.1002/jcb.29564
[21] MEEHAN TF, CONTE N, GOLDSTEIN T, INGHIRAMI G, MURAKAMI MA et al. PDX-MI: Minimal Information for Patient-Derived Tumor Xenograft Models. Cancer Res 2017; 77: e62-e66. https://doi.org/10.1158/0008-5472.CAN-170582

[22] KRUPKE DM, BEGLEY DA, SUNDBERG JP, BULT CJ, EPPIG JT. The Mouse Tumor Biology database. Nat Rev Cancer 2008; 8: 459-465. https://doi.org/10.1038/nrc2390

[23] JIANG Y, ZHAO J, ZHANG Y, LI K, LI T et al. Establishment of lung cancer patient derived xenograft models and primary cell lines for lung cancer study. J Transl Med 2018; 16: 138. https://doi.org/10.1186/s12967-018-1516-5

[24] ZHU QG, ZHANG SM, DING XX, HE B, ZHANG HQ. Driver genes in non-small cell lung cancer: characteristics, detection methods, and targeted therapies. Oncotarget 2017; 8: 57680-57692. https://doi.org/10.18632/oncotarget.17016

[25] POLYAK K, WEINBERG RA. Transition between epithelial and mesenchymal states: acquisition of malignant and stem cell traits. Nat Rev Cancer 2009; 9: 265-273. https://doi. org/10.1038/nrc2620

[26] NURWIDYA F, TAKAHASHI F, MURAKAMI A, TAKAHASHI K. Epithelial mesenchymal transition in drug resistance and metastasis of lung cancer. Cancer Res Treat 2012; 44: 151-156. https://doi.org/10.4143/crt.2012.44.3.151

[27] BEERLING E, SENSTRA D, DE WIT E, KESTER L, VAN DER VELDEN D et al. Plasticity between epithelial and mesenchymal states unlinks EMT from metastasis-enhancing stem cell capacity. Cell Rep 2016; 14: 2281-2288. https://doi. org/10.1016/j.celrep.2016.02.034

[28] TIRAN V LINDENMANN J, BRCIC L, HETZER E, STANZER $S$ et al. Primary patient-derived adenocarcinoma cell culture cancer challenges the association of cancer stem cells with epithelial-to-mesenchymal transition. Sci Rep 2017; 7: 10040. https://doi.org/10.1038/s41598-017-09929-0

[29] GARTNER S, LIU Y, NATESAN S. De novo Generation of Cells within Human Nurse Macrophages and Consequences following HIV-1 Infection. PLoS One 2012; 7: e40139. https://doi.org/10.1371/journal.pone.0040139

[30] SU YC, HSU YC, CHAI CY. Role of the TTF-1, CK20, and CK7 immunohistochemistry for diagnosis of primary and secondary lung adenocarcinoma. Kaohsiung J Med Sci 2006; 22: 14-19. https://doi.org/10.1016/S1607551X(09)70214-1

[31] SI LL, LV L, ZHOU WH, HU WD. Establishment and identification of human primary lung cancer cell culture in vitro. Int J Clin Exp Pathol 2015; 8: 6540-6546.

[32] CARNEY JM, KRAYNIE AM, ROGGLI VL. Immunostaining in Lung Cancer for the Clinician. Commonly Used Markers for Differentiating Primary and Metastatic Pulmonary Tumors. Ann Am Thorac Soc 2015; 12: 429-435. https://doi.org/10.1513/AnnalsATS.201501-004FR

[33] CHU YW, YANG PC, YANG SC, SHYU YC, HENDRIX MJC et al. Selection of invasive and metastatic subpopulation from a human lung adenocarcinoma cell line. Am J Respir Cell Mol Biol 1997; 17: 353-360. https://doi.org/10.1165/ajrcmb.17.3.2837 
[34] CHEN SF, LIN YS, JAO SW, CHANG YC, LIU CL et al. Pulmonary adenocarcinoma in malignant pleural effusion enriches cancer stem cell properties during metastatic cascade. PLoS One 2013; 8: e54659. https://doi.org/10.1371/journal. pone.0054659

[35] XIAO Z, SPERL B, GÄRTNER S, NEDELKO T, STACHERPRIEHSE E et al. Lung cancer stem cells and their aggressive progeny, controlled by EGFR/MIG6 inverse expression, dictate a novel NSLCL treatment approach. Oncotarget 20192; 10: 2546-2560. https://doi.org/10.18632/oncotarget.26817

[36] CARNEY DN, GAZDAR AF, BEPLER G, GUCCION JG, MARANGOS PJ et al. Establishment and Identification of Small Cell Lung Cancer Cell Lines Having Classic and Variant Features. Cancer Res 1985; 45: 2913-2923.

[37] SCHEIDEGGER EP, LACKIE PM, PAPAY J, ROTH J. In vitro and in vivo growth of clonal sublines of human small cell lung carcinoma is modulated by polysialic acid of the neural cell adhesion molecule. Lab Invest 1994; 70: 95-106.

[38] SHANG J, WAN Y, LUO CH, YE G, GENG Q et al. Cell entry mechanisms of SARS-CoV-2. Proc Natl Acad Sci U S A 2020; 117: 11727-11734. https://doi.org/10.1073/pnas.2003138117

[39] LETKO M, MARZI A, MUNSTER V. Functional assessment of cell entry and receptor usage for SARS-CoV-2 and other lineage B betacoronaviruses. Nat Microbiol 2020; 5: 562-569. https://doi.org/10.1038/s41564-020-0688-y

[40] HOFFMAN M, KLEINE-WEBER H, SCHROEDER S, KRUGER N, HERRLER T et al. SARS-CoV-2 cell entrydepends onACE2 and TMPRSS2and is blocked by a clinically proven protease inhibitor. Cell 2020; 181: 271-280.e8. https://doi.org/10.1016/j.cell.2020.02.052

[41] MARTINES RB, RITTER JM, MATKOVIC E, GARY J, BOLLWEG BC et al. Pathology and Pathogenesis of SARSCoV-2 Associated with Fatal Coronavirus Disease, United States. Emerg Infect Dis 2020; 26: 2005-2015. https://doi. org/10.3201/eid2609.202095

[42] LIN W, VOSKENS CJ, ZHANG X, SCHINDLER DG, WOOD A et al. Fc-dependent Expression of CD137 on Human NK Cells: Insights Into "Agonistic" Effects of antiCD137 Monoclonal Antibodies. Blood 2008; 112: 699-707. https://doi.org/10.1182/blood-2007-11-122465

[43] SENBANJO LT, CHELLAIAH MA. CD44: A Multifunctional Cell Surface Adhesion Receptor Is a Regulator of Progression and Metastasis of Cancer Cells. Front Cell Dev Biol 2017; 5: 18. https://doi.org/10.3389/fcell.2017.00018
[44] LEUNG EL, FISCUS RR, TUNG JW, TIN VP, CHENG LC et al. Non-small cell lung cancer cells expressing CD44 are enriched for stem cell-like properties. PLoS One 2010, 5e 14062, https://doi.org/10.1371/journal.pone.0014062

[45] ERAMO A, LOTTI F, SETTE G, PILOZZI E, BIFFONI M et al. Identification and expansion of the tumorigenic lung cancer stem cell population. Cell Death Differ 2008; 15: 504514. https://doi.org/10.1038/sj.cdd.4402283

[46] BERTOLINI G, ROZ L, PEREGO P, TORTORETO M, FONTANELLA E et al. Highly tumorigenic lung cancer CD133+ cells display stem-like features and are spared by cisplatin treatment. Proc Natl Acad Sci U S A 2009; 106: 16281-16286. https://doi.org/10.1073/pnas.0905653106

[47] MENG X, LI M, WANG X, WANG Y, MA D. Both CD133+ and CD133- subpopulations of A549 and H446 cells contain cancer-initiating cells. Cancer Sci 2009; 100: 1040-1046. https://doi.org/10.1111/j.1349-7006.2009.01144.x

[48] ROUDI R, ZAHRA M, MARZEH E, FAZEL S, ALI S. CD44 and CD24 cannot act as cancer stem cell markers in human lung adenocarcinoma cell line A549. Cell Mol Biol Lett 2014; 19: 23-36. https://doi.org/10.2478/s11658-013-0112-1

[49] SONG J, WANG W, WANG Y, QIN Y, WANG Y. Epithelialmesenchymal transition markers screened in a cell-based model and validated in lung adenocarcinoma. BMC Cancer 2019; 19: 680. https://doi.org/10.1186/s12885-019-5885-9

[50] LATTOVÁ E, BRYANT J, SKŘIČKOVÁ J, ZDRÁHAL Z, POPOVIČ M. Efficient Procedure for N-Glycan Analyses and Detection of Endo H-Like Activity in Human Tumor Specimens. J Proteome Res 2016; 15: 2777-2786. https://doi. org/10.1021/acs.jproteome.6b00346

[51] HERREROS-POMARES A, DE-MAYA-GIRONES JD, CALABUIG-FARINAS S, LUCAS R. Lung tumorspheres reveal cancer stem cell-like properties and a score with prognostic impact in resected non-small-cell lung cancer. Cell Death Dis 2019; 10: 660. https://doi.org/10.1038/s41419019-1898-1

[52] LATTOVÁ E, SKŘIČKOVÁ J, HAUSNEROVÁ J, FROLA L, KŘEN L et al. N-Glycan profiling of lung adenocarcinoma in patients at different stages of disease. Mod Pathol 2020; 33: 1146-1156. https://doi.org/10.1038/s41379-019-0441-3

[53] JI J, WERBOWETSKI-OGILVIE TE, ZHONG B, HONG SK, BHATIA M. Pluripotent transcription factors possess distinct roles in normal versus transformed human stem cells. PLoS One 2009; 4: e8065. https://doi.org/10.1371/journal.pone. 0008065 
https://doi.org/10.4149/neo_2021_200906N953

\section{In vivo and in vitro cell-based model of lung adenocarcinoma from patients with pleural effusion}

Mikulas POPOVIC ${ }^{1, \star}$, Yiling LIU ${ }^{1}$, Erika LATTOVA², Dean MANN³, Sabrina CURRELI' ${ }^{1}$, Zbyněk ZDRÁHAL ${ }^{2}$, Martin EDELMAN, ${ }^{5,6}$, Joseph BRYANT ${ }^{1, \star}$

\section{Supplementary Information}
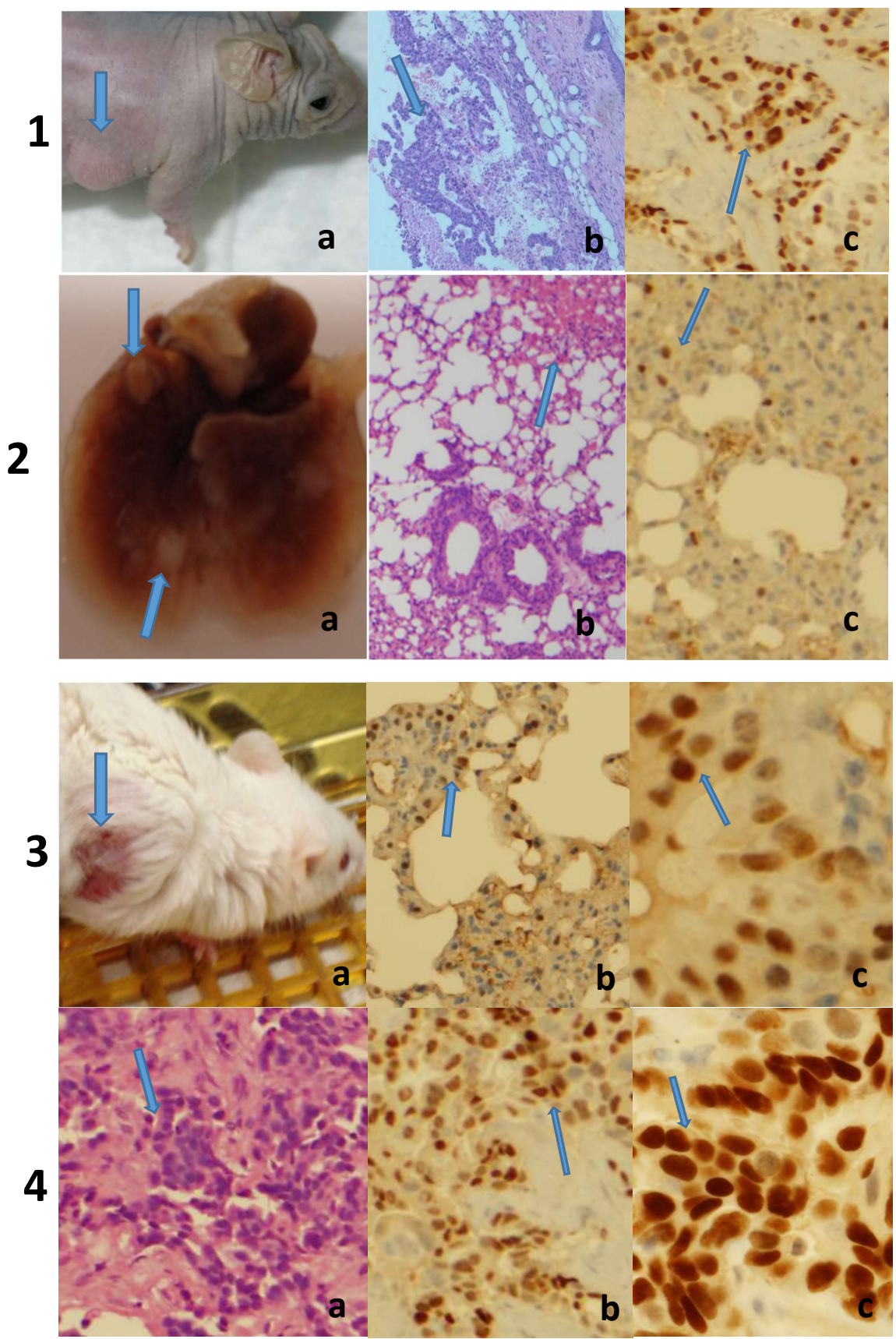

Supplementary Figure S1. Growth of LuCa-3 and LuCa-6 cells following s. c. inoculation in Nude (1a) and NOG (3a) mice, respectively. H\&E and TTF1-stained tumor tissues from s. c. region $(1 \mathrm{~b}, \mathrm{c}[10 \times])$ and from metastatic lung lesions $(2 \mathrm{a}, \mathrm{b}$ and $\mathrm{c}[10 \times])$ of LuCa-3. Staining of LuCa-6 tumor xenografts is shown in lung $(3 b[10 \times]$ and $c[40 \times])$ and s. c. region $(4 a$ and $b[10 \times], c[40 \times])$. Arrows indicate localization of tumors, tumor cells, metastatic lesions in lung (2a) and TTF-1 nuclear staining specific for LAC. 

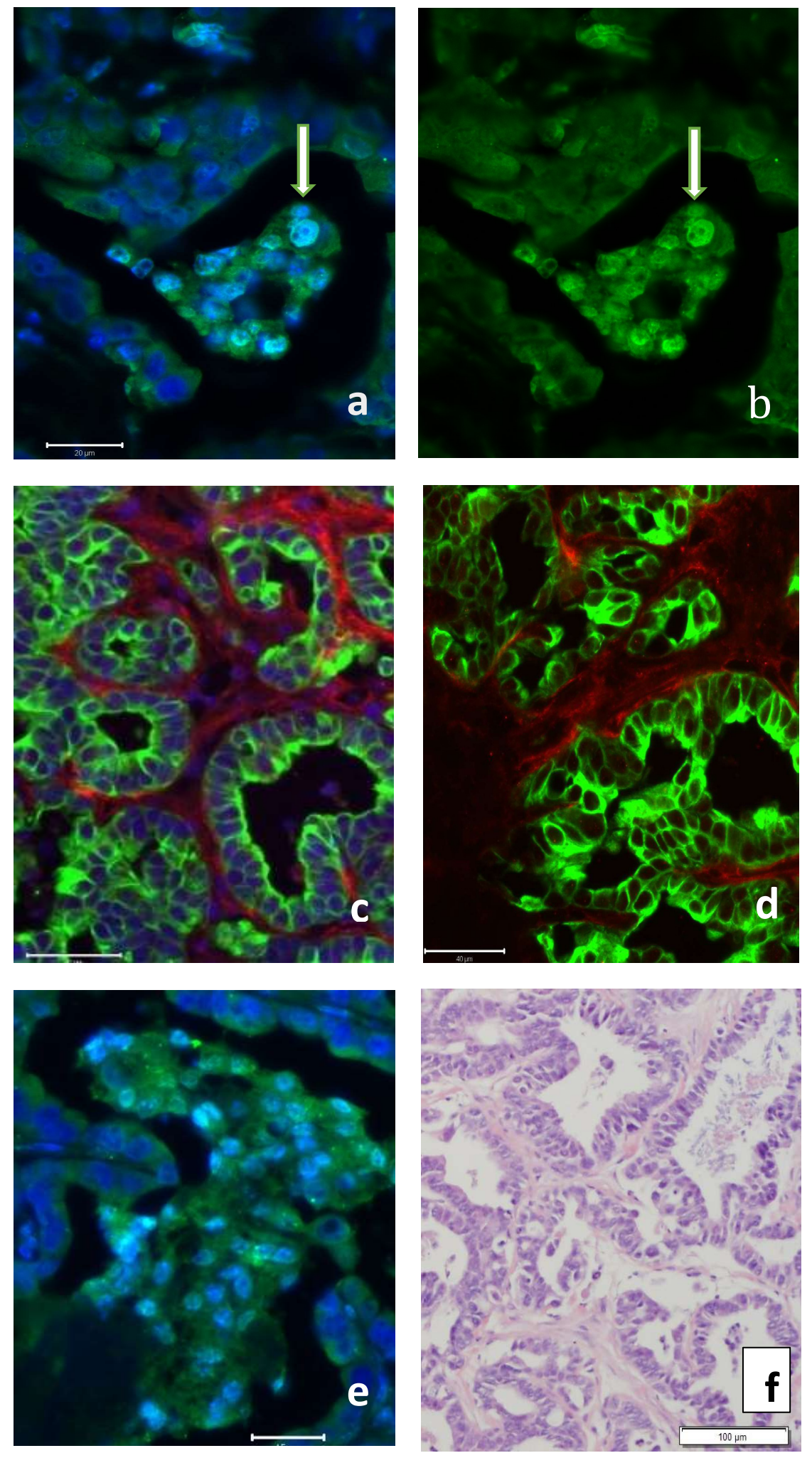

Supplementary Figure S2. Xenograft of LuCa-6S tumor tissue stained for (a) detection of the pluripotent stem marker NANOG, green staining colocalized with nuclear DAPI staining; (b) same image showing NANOG green staining indicated by arrows; (c \& d) display double stained tumor tissue cells for human CK7 keratin (green) and for mouse CD31 endothelial [red (c)] and Er-Tr7 fibroblast [red (d)] cells, respectively. (e) TTF positive cells (green) co-localized with blue DAPI nuclear stain; (f) H\&E staining. Size bars: (a) and (b) $20 \mu \mathrm{m}$, (c) and (d) $40 \mu \mathrm{m},(\mathrm{e}) 15 \mu \mathrm{m}$. 
TTF-1

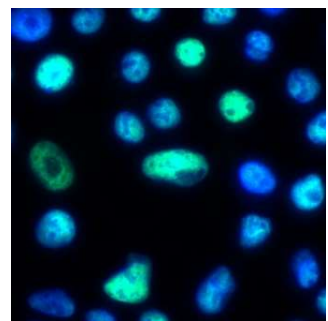

LuCa-6S

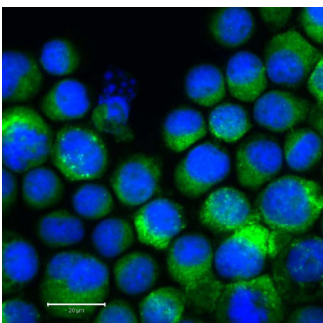

LuCa-6S

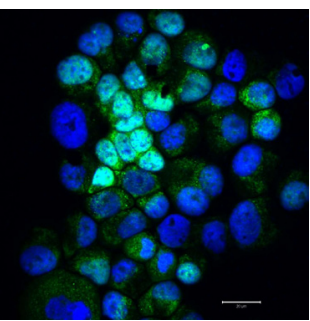

adherent 6-days

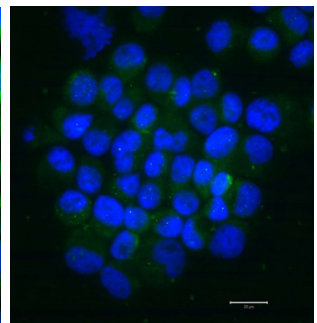

adherent 6-days
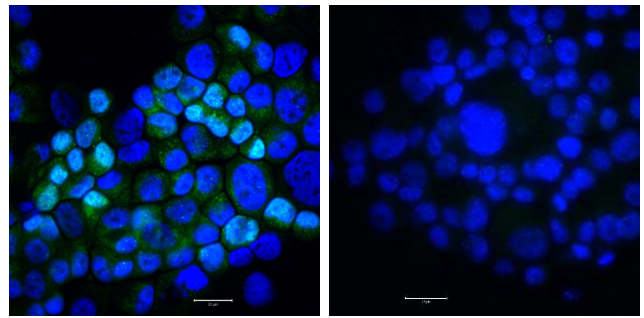

adherent 11-days

LuCa-6A
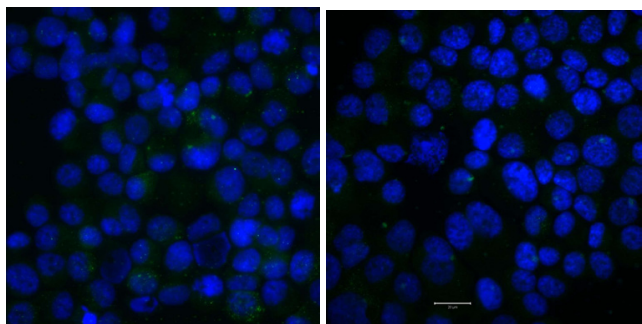

adherent 11-days
LuCa-6A

Supplementary Figure S3. Expression of TTF-1 (thyroid transcription factor 1) localized in nucleus and CD-133 (prominin) in cytoplasmic membrane of LuCa-6S cells converted into an adherent growth pattern. Following short-term culturing of LuCa-6S cells under standard culture conditions (T25 flasks) favoring adherent growth, detections of these markers in the converted cells were performed by IF at days 6 and 11 size bar $20 \mu \mathrm{m}$. Note the rapid decline in expression of TTF- 1 and, particularly CD-133, in process of conversion of LuCa-6S into an adherent LuCa-6A cell culture.

Supplementary Table S1. HLA phenotype.

\begin{tabular}{lll}
\hline Cell line & Class I & Class II \\
\hline LuCa-3 & $A 25, A 68, B 7, B 35$ & Dr4, Dr8, Dr53 \\
LuCa-6 & $A 2, A 23, B 44, B 53$ & Dr7, Dr15, Dr51, Dr53 \\
\hline
\end{tabular}

Notes: The cell lines were derived from L3 and L6 patients, respectively. HLA typing of the established cell lines revealed differing phenotypes and exhibiting only one Class II HLA-Dr53 shared serotype. This makes possible to monitor identity of the cell lines and cultured sublines. As per procedure, the QIAxcel ${ }^{\circledR}$ system (Qiagen) was employed for HLA profile characterization. 

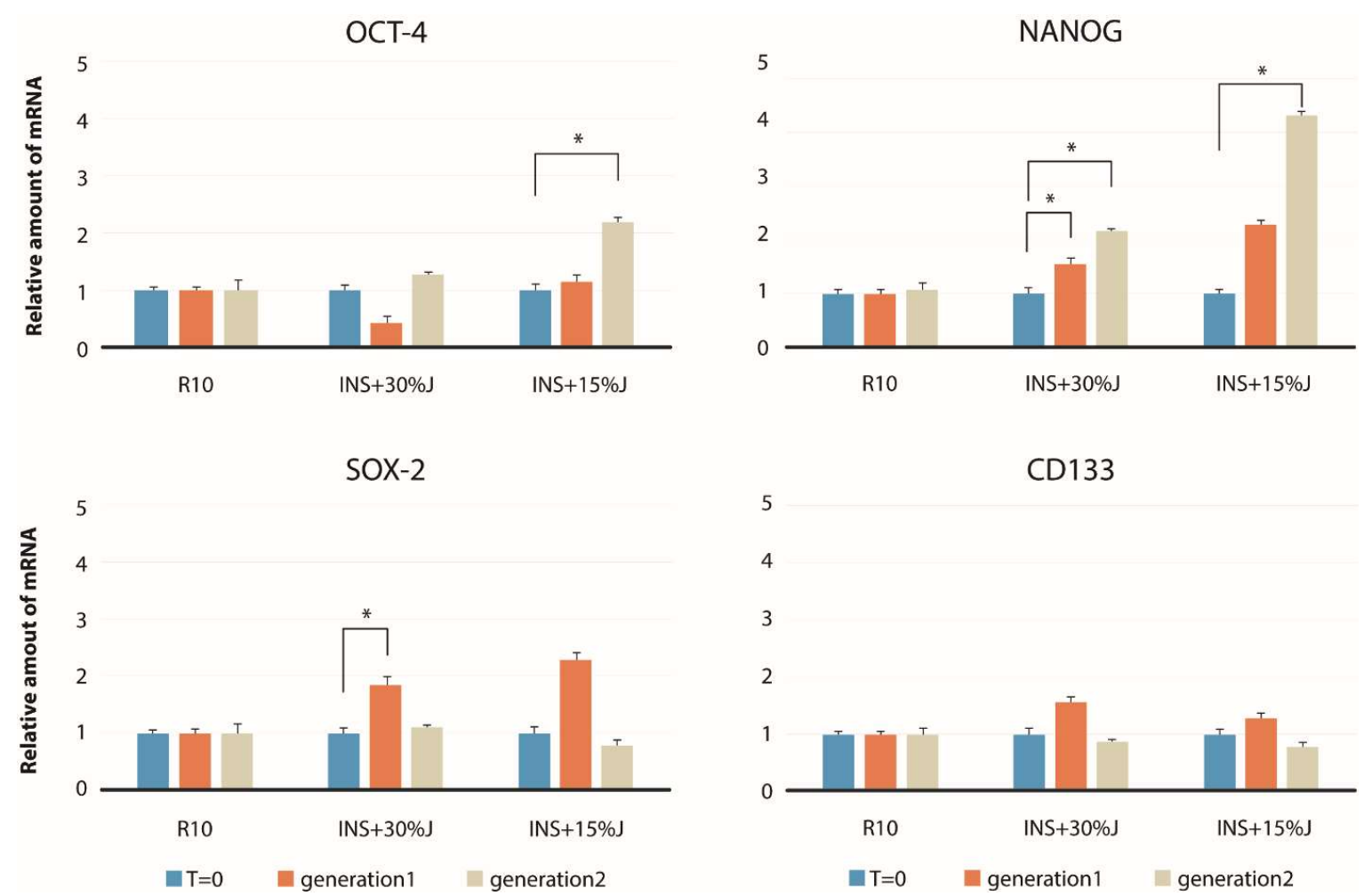

Supplementary Figure S4. Induction of stem cell markers in LuCa-6S cell population. Cells were cultured in standard RPMI1640-CM (R10 blue square) and in matrigel medium with growth factors as follows: matrigel medium $30 \%$ with insulin (INS $+30 \% \mathrm{~J}$ orange square) and matrigel medium $15 \%$ with insulin (INS+15\% J grey square). Concentration of insulin $4 \mu \mathrm{g} / \mathrm{ml}$, epidermal growth factor (EGF) and basic fibroblast growth factor (bFGF) each $20 \mathrm{ng} / \mathrm{ml}$ and human recombinant stem cell factor (hrSCF) $10 \mathrm{ng} / \mathrm{ml}$. Tumor spheres were generated from seeded cells into matrigel medium after 7 days representing "Generation 1" and after 12 days "Generation 2". The second generation of tumor spheres were produced by sub-culturing cells from the first generation. Detection of pluripotent genes (Oct-4, Nanog and Sox-2) and the cell surface transmembrane glycoprotein (prominin) CD133 in LuCa-6S cells was performed by semi-quantitative RT-PCR. The fold change in each mRNA level of induced pluripotent stem cell markers and CD133 compared to the starting seeded cells is shown relative to the change in the expression of beta actin RNA. The level of expression of the RNA encoding the stem cell marker in the starting seeded cells was set to 1 . Data represent the mean $\pm \mathrm{SE}$ of samples run in duplicate and are representative of data from three different experiments. Procedure and primers for pluripotent transcription factors, known as markers for CSC, were previously described by Ji et al. [53]. Note the increased expression of NANOG at RNA level in cells of tumor spheres in Generation 2. [ $\left.{ }^{*} \mathbf{p}<0.05\right]$.

Supplementary Figure S5. IF detection of SOX-2 in cells of clone 3 obtained by limiting dilution from LuCa-6S grown in suspension (see Figure 1). Cells were stained for SOX-2 and CD-133 with two colors. Upper left shows nuclear localization of SOX-2 (green) and DAPI (blue). Upper right shows CD133 (red) and DAPI staining. Bottom left is shown staining for two (SOX-2 and CD-133) and bottom right for three (SOX2, CD-133, DAPI) colors, size bar: $20 \mu \mathrm{m}$. Note nuclear localization of SOX-2 stained also with DAPI and its absence in cells stained for membrane CD-133 and nucleus with DAPI. Double (SOX-2+CD-133) and triple (SOX-2+CD-133+Dapi) staining clearly demonstrate nuclear expression of SOX-2 in majority of cells. This cloned cell population was sub-cultured in ratio 1:3 in CM-RPMI-1640, maintained in culture for 4-days and then processed for IF analyses.7.

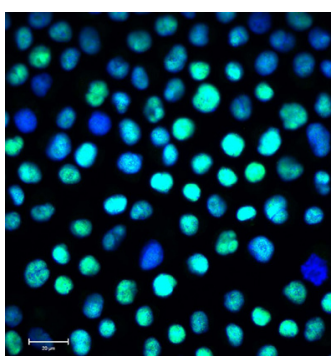

SOX-2+DAPI

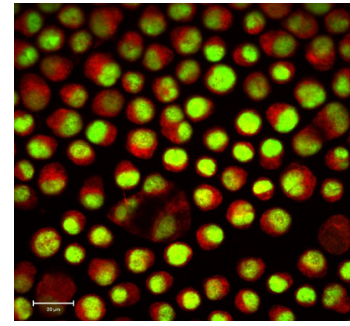

SOX-2+CD-133

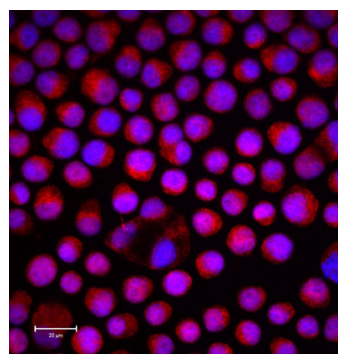

CD-133+DAPI

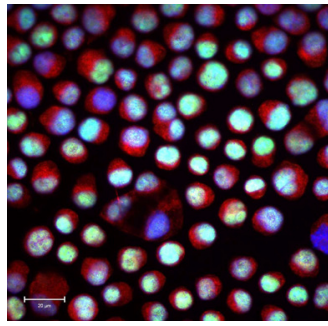

SOX-2+CD-133+DAPI 
I)

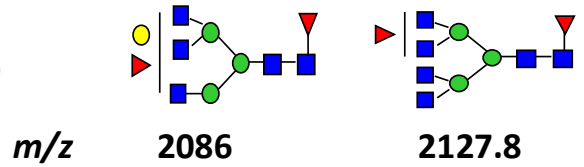

II)

$\begin{array}{ll} & 0001 \\ m / z & 1007\end{array}$

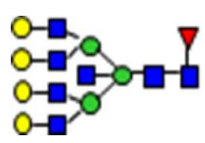

$m / z$
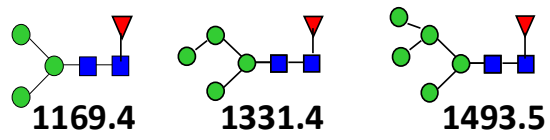

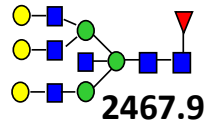

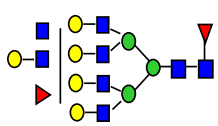

3344.2
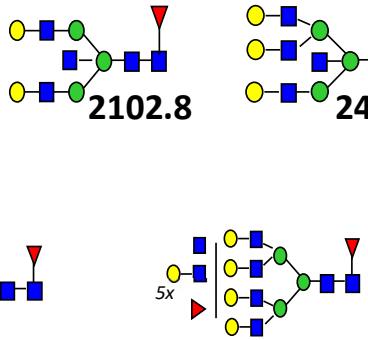

3928.4

Supplementary Figure S6. Depicted structures of $\mathrm{N}$-glycans with $\mathrm{m} / \mathrm{z}$ values distinguished according to relative abundance in cells of sublines: $\mathrm{I}$ ) LuCa-6S growing in suspension and II) LuCa-6A adherent one. The $\mathrm{m} / \mathrm{z}$ values in red are $\mathrm{N}$-glycans detected only in the adherent form. Procedures for glycan release from cell specimens, extractions and subsequent steps of sample preparations for mass spectrometry (MS) and data analysis were described previously (see Lattova et al. [50, 52]). MALDI-TOF-MS spectra of N-glycans with a range of m/z 1000-4120 were recorded. All glycan peaks are detected as MNa+. Key symbols: Fuc: ; GlcNac: ; Gal: ; Man: Notes: Ten N-glycans were detected in the LuCa-6A cell population, eight of them were in abundance and present at low, but detectable level in the LuCa-6S population. In addition, two complex $\mathrm{N}$-glycans with high $\mathrm{m} / \mathrm{z}$ values were detected only in the LuCa-6A cell population, while only two $\mathrm{N}$-glycans were detected in abundance in LuCa-6S cell populations which were detected at low level in the LuCa-6A subline.

100

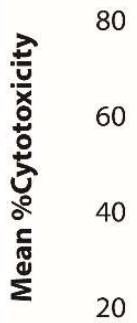

20

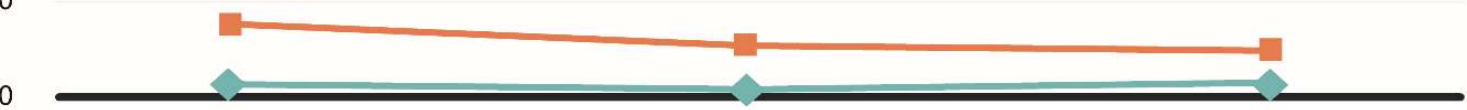

$10: 1$

INS+30\%J

INS+15\%J

E:T

K562 LuCa-6A LuCa-6S

Supplementary Figure S7. Test of NK cytolytic activity against tumor cell lines of LAC: positive control K562 cells (blue line), adherent growing LuCa-6A (pink line) and in suspension form LuCa-6S (green line) were tested by standard 4-hour Chromium release assay at day 14. NK effector cells obtained from donor Aph030409 and expanded in SCGM as described by Lin et al [42]. Data represent average of 3 independent experiments. 